\title{
MASTER
}

$\frac{\text { PNL-3165 }}{\text { UC-23 }}$

\section{Collapse of Experimental Capsules Under External Pressure}

\section{F. A. Simonen}

R. J. Shippell, Jr.

January 1980

Prepared for the U.S. Department of Energy under Contract EY-76-C-06-1830

Pacific Northwest Laboratory Operated for the U.S. Department of Energy by Battelle Memorial Institute 


\section{DISCLAIMER}

This report was prepared as an account of work sponsored by an agency of the United States Government. Neither the United States Government nor any agency Thereof, nor any of their employees, makes any warranty, express or implied, or assumes any legal liability or responsibility for the accuracy, completeness, or usefulness of any information, apparatus, product, or process disclosed, or represents that its use would not infringe privately owned rights. Reference herein to any specific commercial product, process, or service by trade name, trademark, manufacturer, or otherwise does not necessarily constitute or imply its endorsement, recommendation, or favoring by the United States Government or any agency thereof. The views and opinions of authors expressed herein do not necessarily state or reflect those of the United States Government or any agency thereof. 


\section{DISCLAIMER}

Portions of this document may be illegible in electronic image products. Images are produced from the best available original document. 
This report was prepared as an account of work sponsored by the United States Government. Neither the United States nor the Department of Energy, nor any of their employees, nor any of their contractors, subcontractors, or their employees, makes any warranty, express or implied, or assumes any legal liability or responsibility for the accuracy, completeness or usefulness of any information, apparatus, product or process disclosed, or represents that its use would not infringe privately owned rights.

The views, opinions and conclusions contained in this report are those of the contractor and do not necessarily represent those of the United States Government or the United States Department of Energy.

\title{
PACIFIC NORTHWEST LABORATORY \\ operated by \\ BATTELLE \\ for the
}

UNITED STATES DEPARTMENT OF ENERGY

Under Contract EY-76-C-06-1830

\author{
Printed in the United States of America \\ Available from \\ National Technical Information Service \\ United States Department of Commerce \\ 5285 Port Royal Road \\ Springfield, Virginia 22151
}

Price: Printed Copy $\$$

*: Microfiche $\$ 3.00$

\begin{tabular}{lr} 
*Pages & \multicolumn{1}{c}{ NTIS } \\
& Selling Pric \\
$001-025$ & $\$ 4.00$ \\
$026-050$ & $\$ 4.50$ \\
$051-075$ & $\$ 5.25$ \\
$076-100$ & $\$ 6.00$ \\
$101-125$ & $\$ 6.50$ \\
$126-150$ & $\$ 7.25$ \\
$151-175$ & $\$ 8.00$ \\
$176-200$ & $\$ 9.00$ \\
$201-225$ & $\$ 9.25$ \\
$226-250$ & $\$ 9.50$ \\
$251-275$ & $\$ 10.75$ \\
$276-300$ & $\$ 11.00$
\end{tabular}


PNL -3765

UC -23

MASTER

COLLAPSE OF EXPERIMENTAL CAPSULES

UNDER EXTERNAL PRESSURE

F. A. Simonen

R. J. Shippel1, Jr.

January 1980

Prepared for

the U.S. Department of Energy under Contract EY-76-C-06-1830

Pacific Northwest Laboratory

Richland, Washington 99352

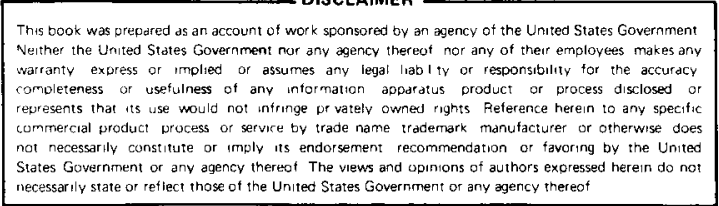
Wecessarly state or reflect those of the United States Government or any agency thereo 
page blank 
Stress analyses and developmental tests of capsules fabricated from thick-walled tubing were performed for an external pressure design condition. In the design procedure no credit was taken for the expected margin in pressure between yielding of the capsule wall and catastrophic collapse or flattening. In tests of AISI-1018 low carbon steel capsules, a significant margin was seen between yield and collapse pressure. However, the experimental yield pressures were significantly below predictions, essentially eliminating the safety margin present in the conservative design approach.

The differences between predictions and test results are attributed to deficiencies in the plasticity theories commoniy in use for engineering stress analyses. The results of this study show that the von Mises yield condition does not accurately describe the yield behavior of the AISI-1018 steel tubing material for the triaxial stress conditions of interest.

Finite element stress analyses successfully predicted the transition between uniform inward plastic deformation and ovalization that leads to catastrophic collapse. After adjustments to correct for the unexpected yield behavior of the tube material, the predicted pressure-deflection trends were found to follow the experimental data. 
page blank 


\section{CONTENTS}

SUMMARY...................... . . . . . . .

FIGURES. .......................... . . . . . .

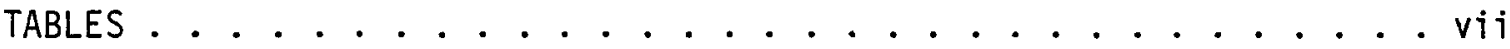

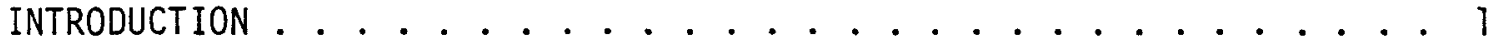

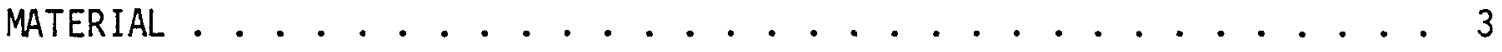

CAPSULE COLLAPSE TEST CONDITIONS ............. 5

CAPSULE COLLAPSE TEST RESULTS. . . . . . . . . . . . 9

STRESS ANALYSIS. . . . . . . . . . . . . . . . . . 15

PREDICTED VERSUS EXPERIMENTAL COLLAPSE . . . . . . . . 17

POSSIBLE SOURCES OF ERROR. . . . . . . . . . . . . 23

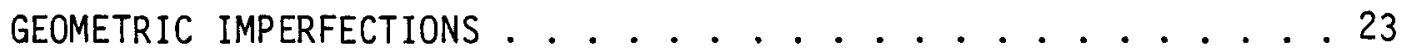

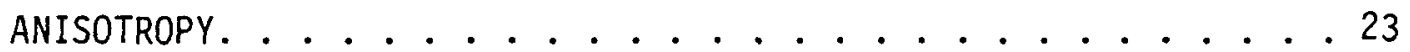

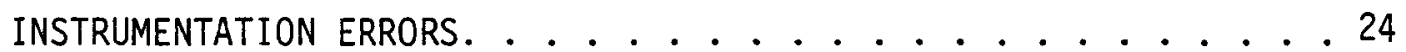

HEAT TREATMENT NOT AS SPECIFIED . . . . . . . . . . . 24

IDENTIFICATION OF COMPRESSION SPECIMENS . . . . . . . 24

END CAP EFFECTS . . . . . . . . . . . . . . . . 24

DETECTION OF YIELDING IN CAPSULES . .......... 25

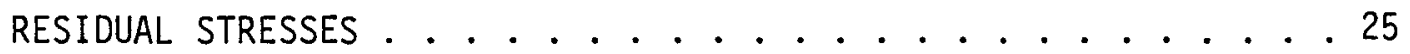

YIELD CRITERIA. . . . . . . . . . . . . . . . 25

DISCUSSION . . . . . . . . . . . . . . . 27

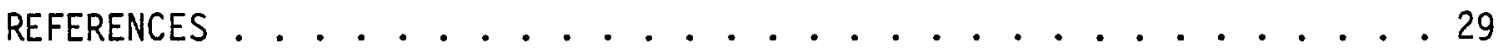


page blank 


\section{FIGURES}

1 Typical Tensile Stress-Strain Curve for AISI-1018 Carbon Steel Tubing. ................ 3

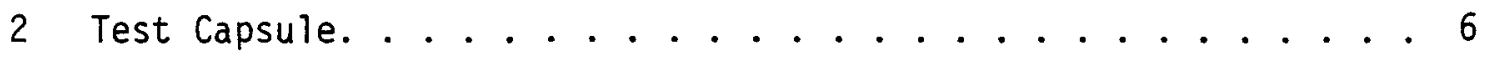

3 Outer Capsule Components and Completed AISI-1018 Steel Outer Capsule Ready for Pressure Testing. . . . . . . . . . . . 7

4 Steel Capsules After Pressure Testing . . . . . . . . . . . . 10

5 Measured Average Diameter Changes in AISI-1018 Steel Test Capsules. . . . . . . . . . . . . . . . . . 11

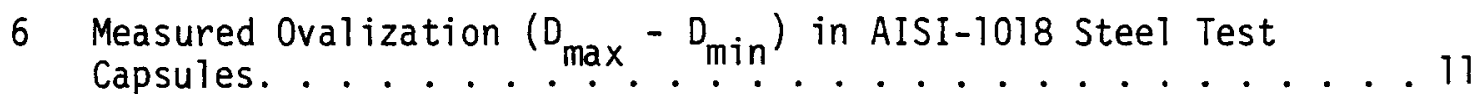

7 Experimental Yield and Collapse Pressures for AISI-1018 Stee1 Test Capsules . . . . . . . . . . . . . . . . 12

8 Strain Grid Data From Outer Surface of 0.5-Inch Wall Capsules . . 14

9 Comparison of Predicted and Measured Yield Pressures for AISI1018 Steel Test Capsules. . . . . . . . . . . . . . 18

10 Comparison of Predicted and Measured Average Diameter Changes for AISI-1018 Steel Test Capsules . . . . . . . . . . . 20

11 Comparison of Predicted and Measured Ovalization of AISI-1018 Steel Test Capsules................. 21

\section{TABLES}

1 Yield Strengths of AISI-1018 Carbon Steel Tubing. . . . . . . 4

2 Capsule Dimensions. . . . . . . . . . . . . 5

3 Capsule Experimental Failure Pressures. . . . . . . . . . 13 


\section{COLLAPSE OF EXPERIMENTAL CAPSULES UNDER \\ EXTERNAL PRESSURE}

\section{INTRODUCTION}

Pacific Northwest Laboratories (PNL), under sponsorship of the U.S. Department of Energy, is developing an outer capsule for an isotope powered heat source. The structural design and stress analys is of the capsule are discussed by Simonen (1979). Nuclear Regulatory Commission regulations require that the capsule sustain an external pressure of 1000 bars $(14,500 \mathrm{psi})$. The capsule wall thickness must be selected to meet this pressure requirement. This report describes studies conducted by PNL to predict and determine experimental collapse pressures of thick-walled capsules designed for the described application.

The collapse behavior of thick-walled tubes has been reviewed by Heise and Esztergar (1979). Under external pressure, the inside diameter of a thick-walled tube will experience the highest stress, and the tube wall will first yield at this location. Under increasing pressure, the yielded region of the tube wall will continue to expand toward the outside diameter until the entire wall thickness of the tube is plastically deformed.

Once the cross section of a thick-walled tube is fully yielded, increasing pressure will at first collapse the tube uniformly inward. However, small nonuniformities in the tube (initial ovalization of the cross section, wall thickness variations, or variations in material properties) will cause the tube to begin to ovalize or flatten. In general, the thicker the tube wall (relative to its diameter) and the higher the rate of strain hardening in the material, the greater will be the resistance of the tube to such ovalization. In contrast for thinwall tubing, ovalization and collapse can occur as a result of an elastic instability prior to yielding of the tube wall. For thin-wall tubes such instabilities are very sensitive to initial manufacturing imperfections 
in shape of the tube cross section. Data reported in the literature for tube thicknesses used in this study indicate that the collapse of such tubes is not sensitive to small imperfections.

Analyses and experiments were performed in this study for capsules of AISI-1018 carbon steel. This material was selected as a stand-in for a prototype capsule of Hastelloy $S^{\otimes}$ which, in an aged condition, will have a similar yield strength of $40,000 \mathrm{psi}$. The objective of this report is to document the observed trends so that comparisons with similar tests and alternative prediction methods can be made in future studies at PNL and elsewhere.

In this report, the results of the collapse experiments for the AISI-1018 capsules are first presented. Then, predictions by various experimental methods are described. Finally, the experimental results and predictions are compared and reasons for lack of agreement are discussed.

\footnotetext{
${ }^{\circledR}$ Trade name of Stellite Division of Cabot Corporation.
} 


\section{MATERIAL}

Test capsules were fabricated of AISI-1018 commercial steel tubing. The tubing was purchased with a finished inside diameter of 2.375 inches and an outside diameter of 3.750 inches. Final outside diameters of the test capsules were obtained by machining to size.

The fabrication process for the tubing was not known. Such tubing would, however, be typically extruded or pierced, or both. All material used in capsule pressure tests and mechanical property tests was annealed at $1500^{\circ} \mathrm{F}$ for 1 hour and furnace-cooled. No chemical analyses of metallographic characterization were performed.

Figure 1 shows the result of a tensile test performed at PNL, which gives a representative tensile stress-strain curve for the steel tubing used. Yield strengths in tension and compression are given in Table 1. Two tensile yield strengths are given; both specimens received the same nominal annealing treatment. Tensile strengths were determined from two specimens cut to measure properties in the longitudinal direction of the

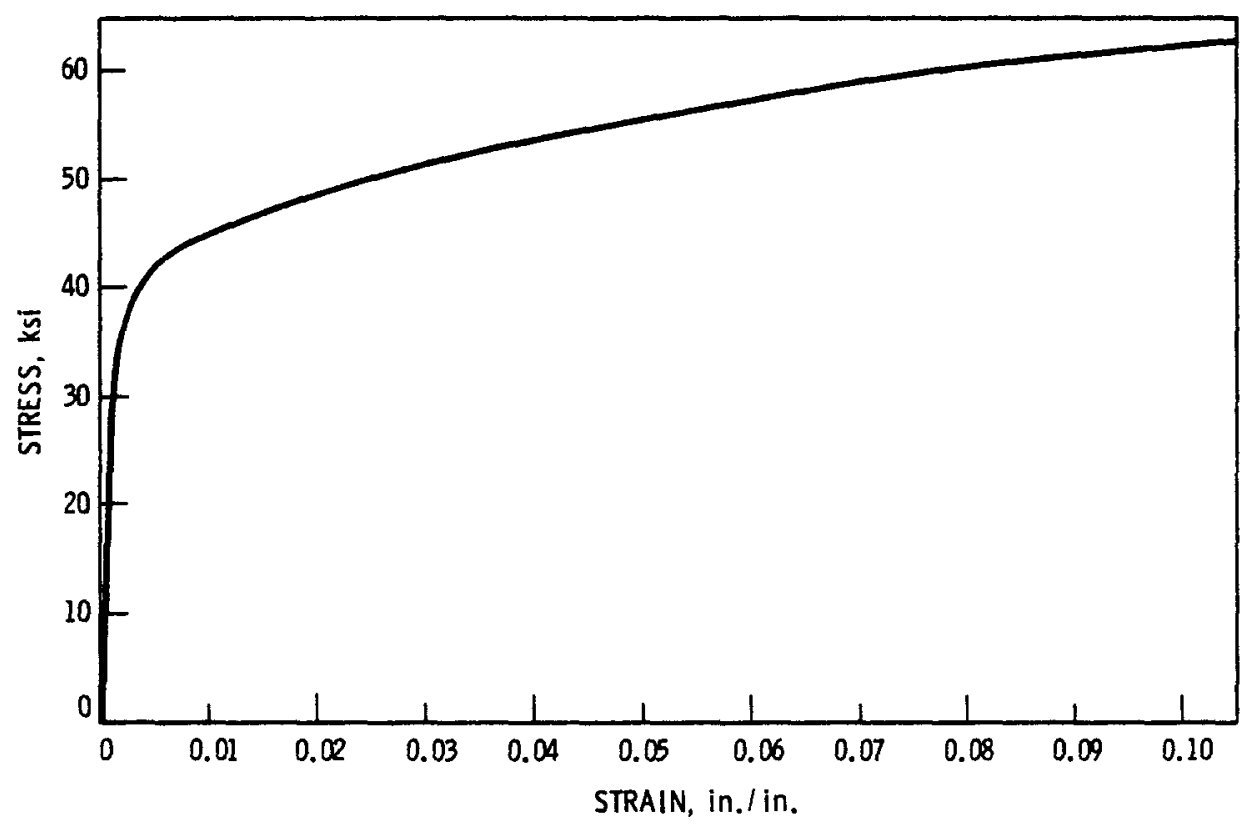

FIGURE 1. Typical Tensile Stress-Stra in Curve for AISI-1018 Carbon Steel Tubing 
TABLE 1. Yield Strengths of AISI-1018

Carbon Steel Tubing Material

\begin{tabular}{lccc} 
& \multicolumn{3}{c}{ Yield Strength, psi } \\
\cline { 2 - 4 } & Longitudinal & Circumferential & Radial \\
$\begin{array}{c}\text { Tension Test - Annealed Sample } \\
\text { of Tubing }\end{array}$ & 41,350 & - \\
$\begin{array}{c}\text { Tension Test - 0.6-in. Wall } \\
\text { Capsule }\end{array}$ & 40,400 & - \\
$\begin{array}{c}\text { Compression Test - 0.6-in. Wall } \\
\text { Capsule }\end{array}$ & 37,800 & 39,400 & 33,900
\end{tabular}

capsule. The first specimen was cut from an extra piece of the tubing material. The second test specimen was cut from the 0.6 -inch wall test capsule after external pressure testing had caused some plastic deformation (on the order of 4 percent).

Three miniature compression test specimens were cut from the 0.6 -inch wall test capsule to measure directional yield strengths. Specimen dimensions were 0.5 -inch long by 0.2 -inch diameter. Table 1 lists yield strengths in the longitudinal, circumferential, and radial directions of the tubing material. Except for the radial compressive yield strength of $33,900 \mathrm{psi}$, the compressive strengths were comparable to the measured longitudinal tensile strength. The yield strengths may have been affected by the previous plastic deformation of capsule material in the external pressure test. However, this effect is thought to be minimal for the compression specimens because they were cut from the capsule wall near the end caps, where restraining effects of the ends essentially prevented plastic deformation of the wall. 


\section{CAPSULE COLLAPSE TEST CONDITIONS}

Three test capsules as shown in Figures 2 and 3 were fabricated from the AISI-1018 carbon steel. Table 2 summarizes the initial physical dimensions of the test capsules. As noted, all capsules had the same inside diameter (2.375 inches).

\section{TABLE 2. Capsule Dimensions}

\begin{tabular}{|c|c|c|c|}
\hline & $\begin{array}{l}0.4-\text { Inch } \\
\text { Wall } \\
\end{array}$ & $\begin{array}{l}0.5-\text { Inch } \\
\text { Wall } \\
\end{array}$ & $\begin{array}{l}0.6-\text { Inch } \\
\text { Wall } \\
\end{array}$ \\
\hline Inside Diameter, inch & 2.375 & 2.375 & 2.375 \\
\hline Outside Diameter, inch & 3.175 & 3.375 & 3.575 \\
\hline $\begin{array}{l}\text { Measured Bore Eccentricity, } \\
\text { inch }\end{array}$ & 0.005 & 0.011 & 0.0045 \\
\hline
\end{tabular}

External pressure tests were performed at the Civil Engineering Laboratory, U.S. Naval Construction Battalion Center, Port Hueneme, California. A 9-inch vesse 1 rated at 20,000 psi was pressurized with water at room temperature. Pressures were monitored and recorded from two independent pressure gages. All tests were conducted in the presence of PNL staff.

Each capsule was pressurized in 1000-psi increments starting at $10,000 \mathrm{psi}$. After each pressurization, the capsules were removed from the vessel and the permanent diameter changes were measured using a micrometer. Diameters were measured at $45^{\circ}$ increments to observe the onset of ovalization of the capsule cross sections. The pressure was increased incrementally to 20,000 psi or until the capsules experienced total collapse in the form of flattening.

Al1 capsules were checked after testing with a helium system capable of detecting leaks of less than $1 \times 10^{-8} \mathrm{cc} / \mathrm{sec}$. No leaks were detected. 


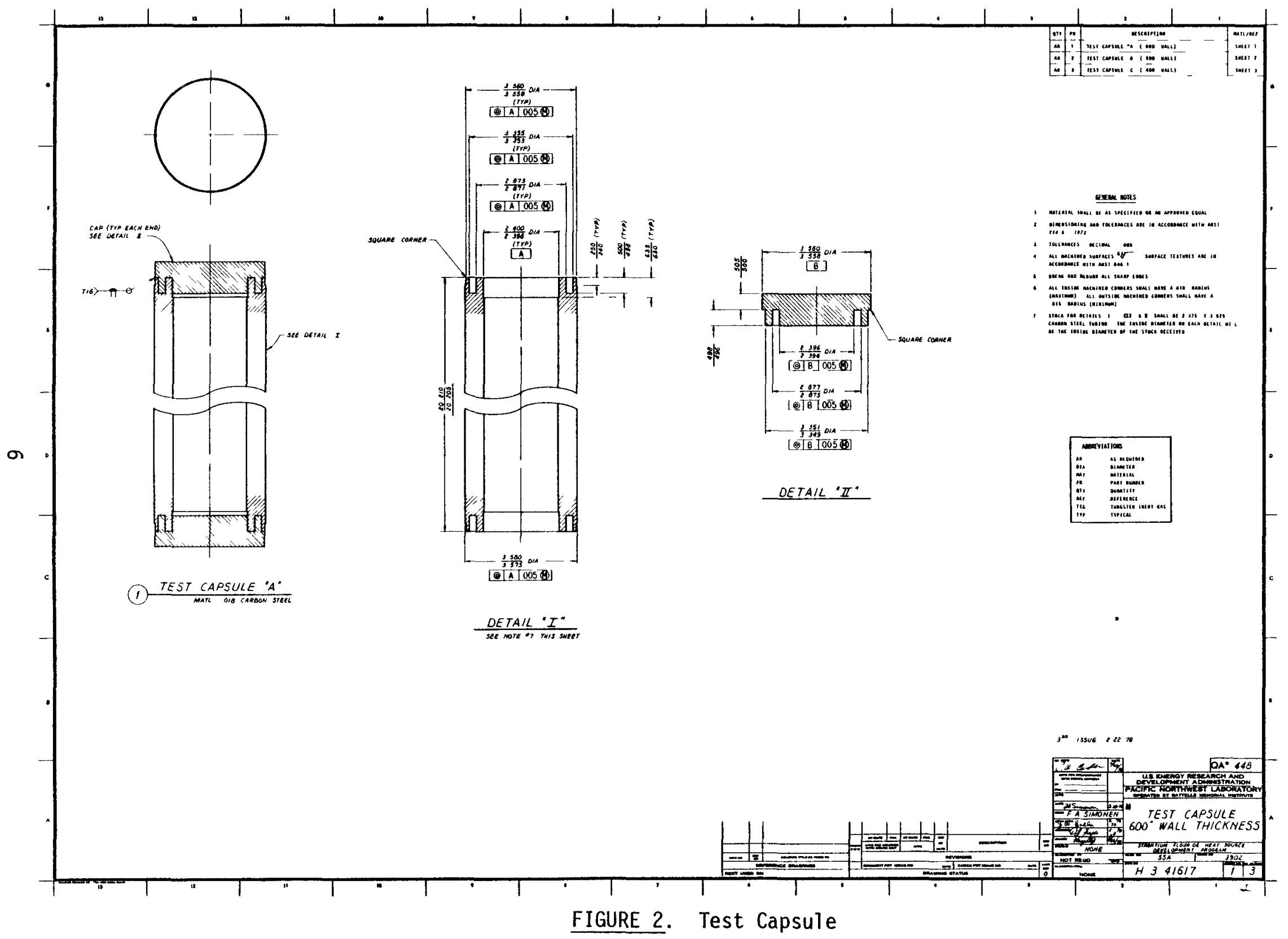




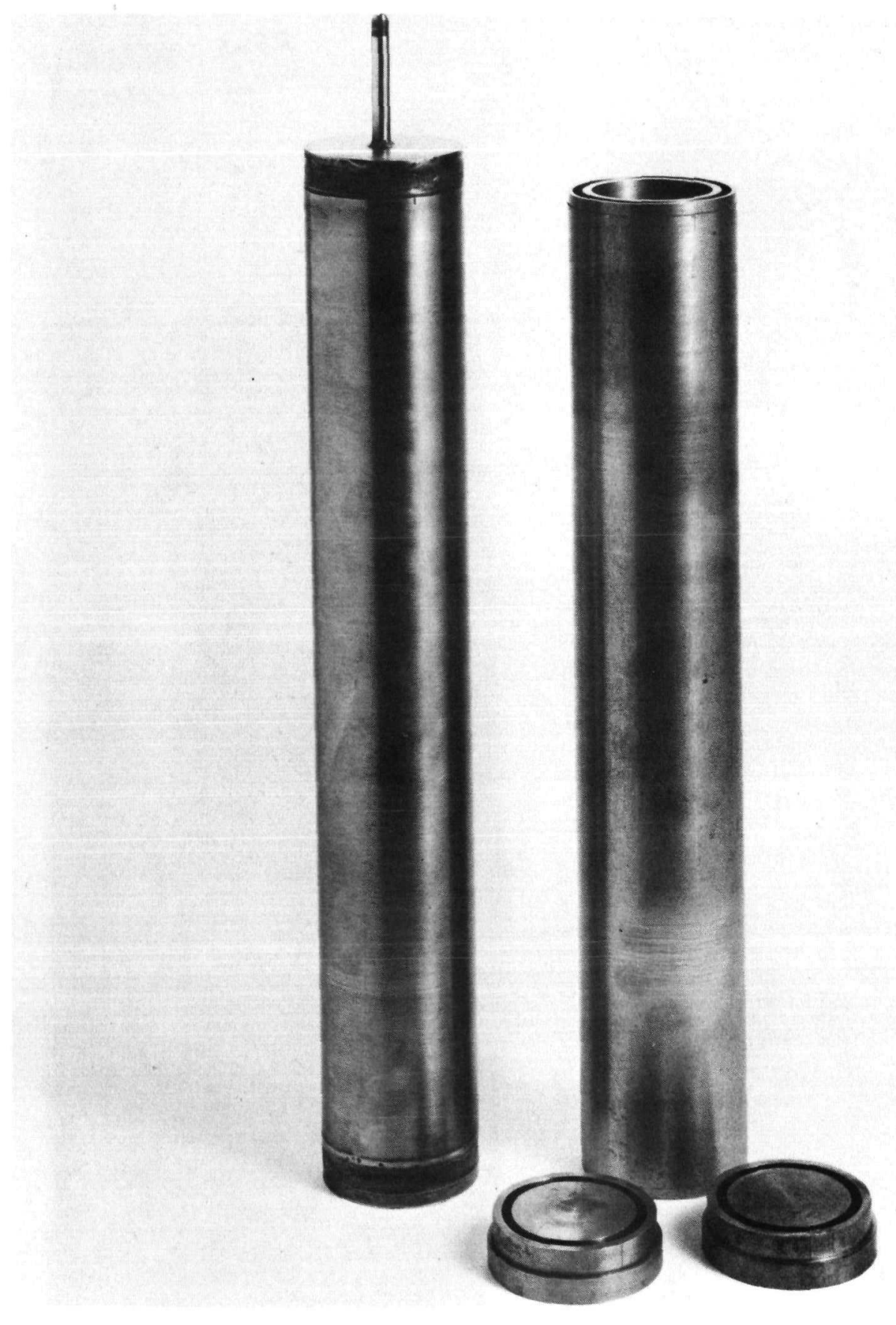

FIGURE 3. Outer Capsule Components and Completed AISI-1018 Steel Outer Capsule Ready for Pressure Testing 
page blank 


\section{CAPSULE COLLAPSE TEST RESULTS}

The capsules after external pressure testing are shown in Figure 4. An electrochemically etched grid used to measure external surface strains is visible on the capsule surfaces.

Maximum and minimum diameters of the capsules were measured at 1000-psi increments in pressure using a micrometer. Figures 5 and 6 show the measured average diameter change and the differential diameter change (a measure of ovalization).

A permanent average diameter change of 0.010 inch was selected as the criterion for full yielding of the capsule wall. This deformation level was we11 above the yield strain (yield strength/elastic modulus) for the material, and was consistent with trends of finite element calculations for full yielding in the capsule wall.

Figure 6 shows that the ovalization developed gradually with increasing pressure. In the final collapse, complete flattening of the circular cross section occurred with opposite sides of the capsule coming into contact. The 0.6-inch wall did not fully flatten at the 20,000-psi maximum pressure rating of the test vessel. The collapse pressure of 20,500 was estimated on the basis of the trend of the ovalization curve. For the two thinner capsules, collapse was noted during the test by a sudden drop in the pressure gage readings; the pumping apparatus could not sustain pressure while the capsule volume decreased. The 0.4-inch capsule collapsed violently. A sharp metallic sound was heard as the sides of the capsule impacted. Collapse of the 0.5 -inch wall capsule proceeded in a more stable manner.

Figure 7 and Table 3 give the experimental pressures for both a fully plastic wall and for catastrophic collapse as a function of wall thickness. Both pressures, as expected, increased with increasing wall thickness. The margin between ful1-wa11 plasticity and catastrophic collapse showed a particularly significant increase with wall thickness. This is attributed to the fact that the bending stiffness of the capsule wall is a function of 

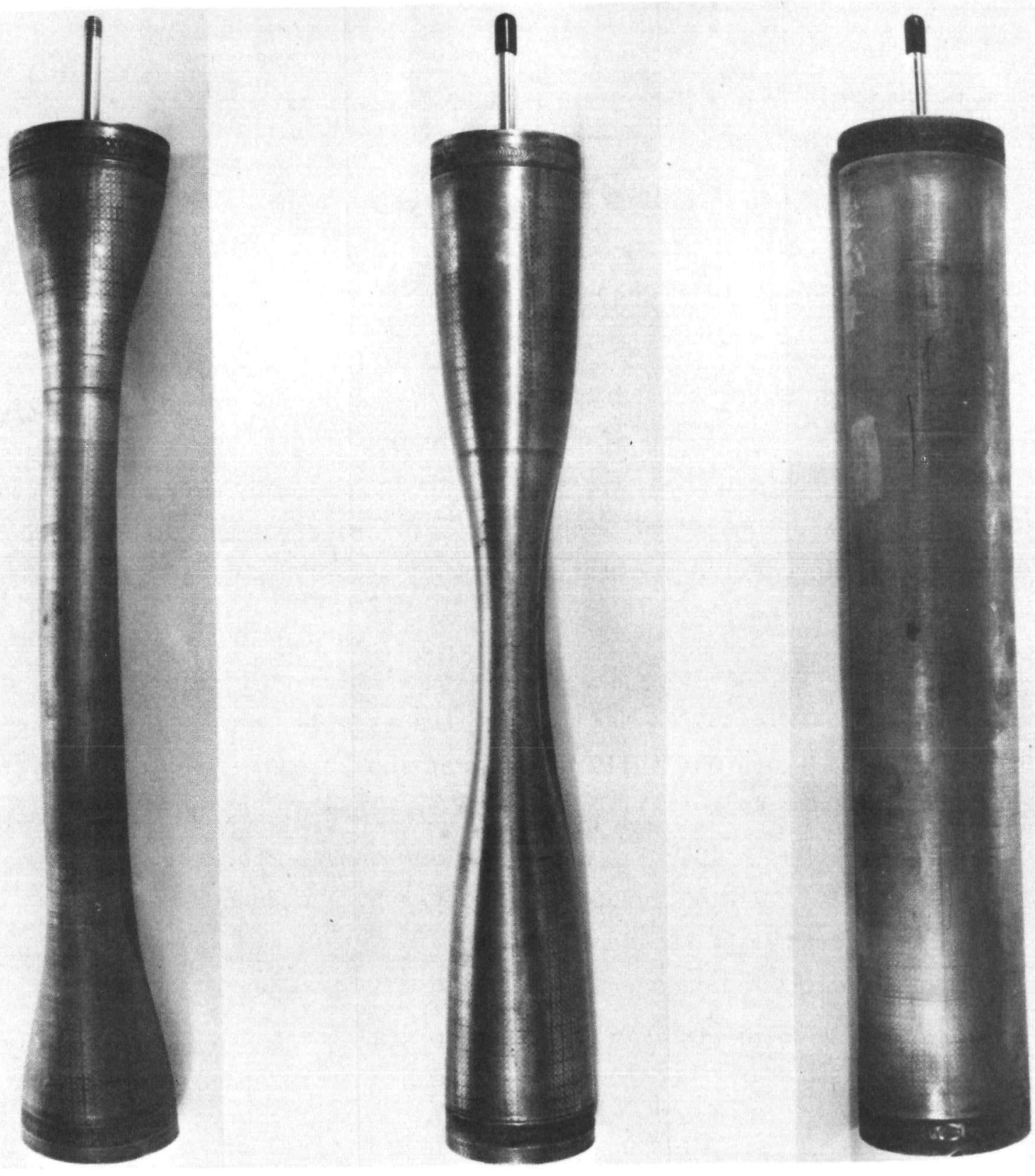

FIGURE 4. Steel Capsules After Pressure Testing 


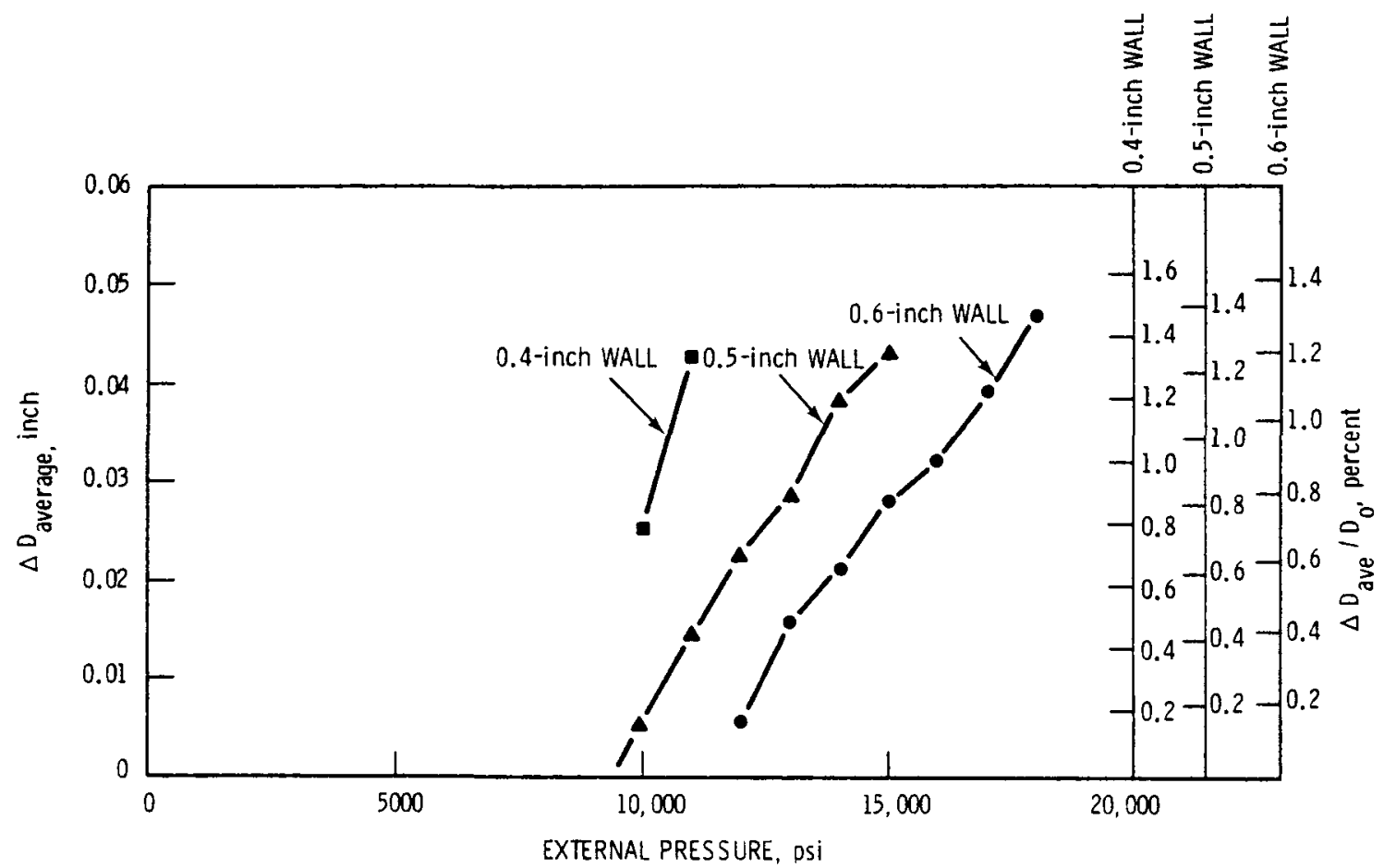

FIGURE 5. Measured Average Diameter Changes in AISI-1018 Steel Test Capsules

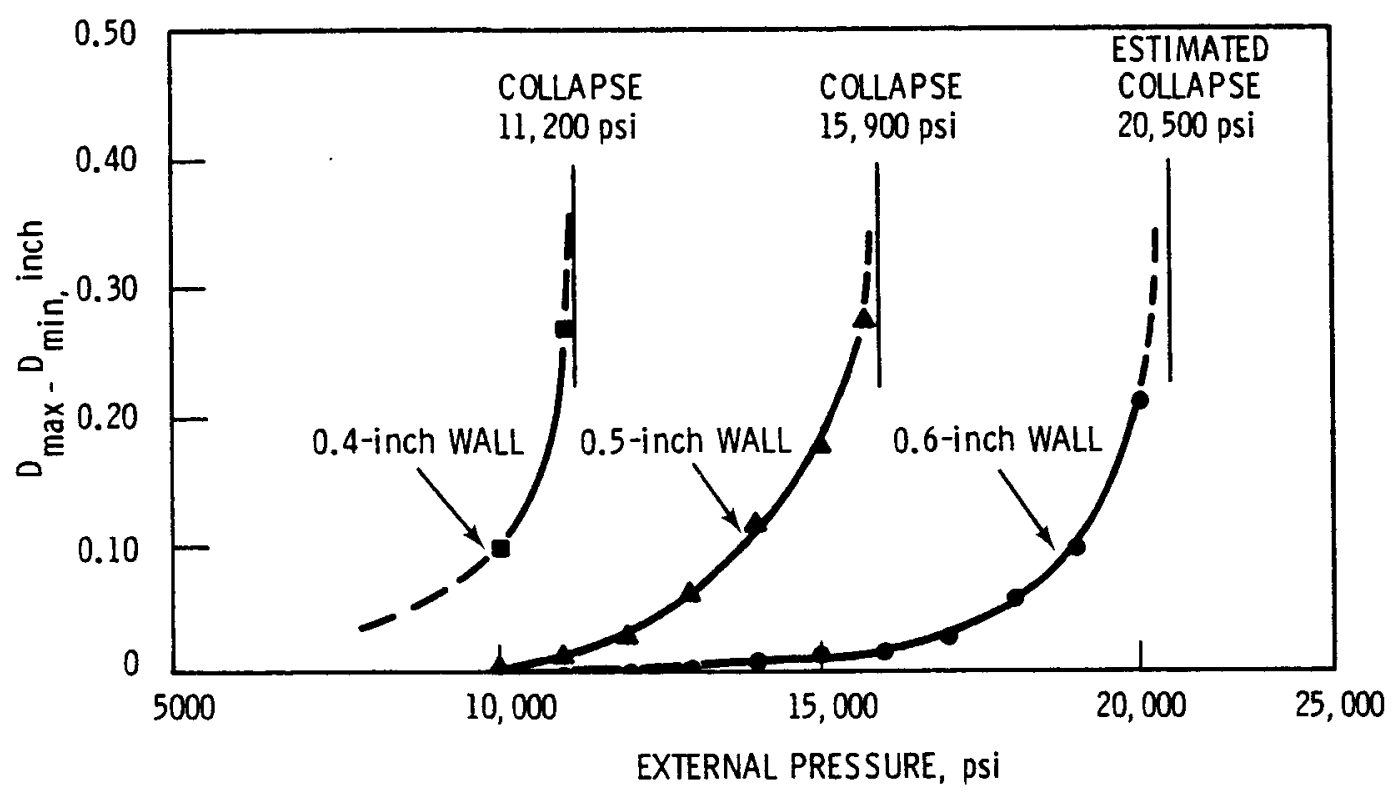

FIGURE 6. Measured Ovalization $\left(D_{\max }-D_{\min }\right)$ in AISI-1018 Steel 


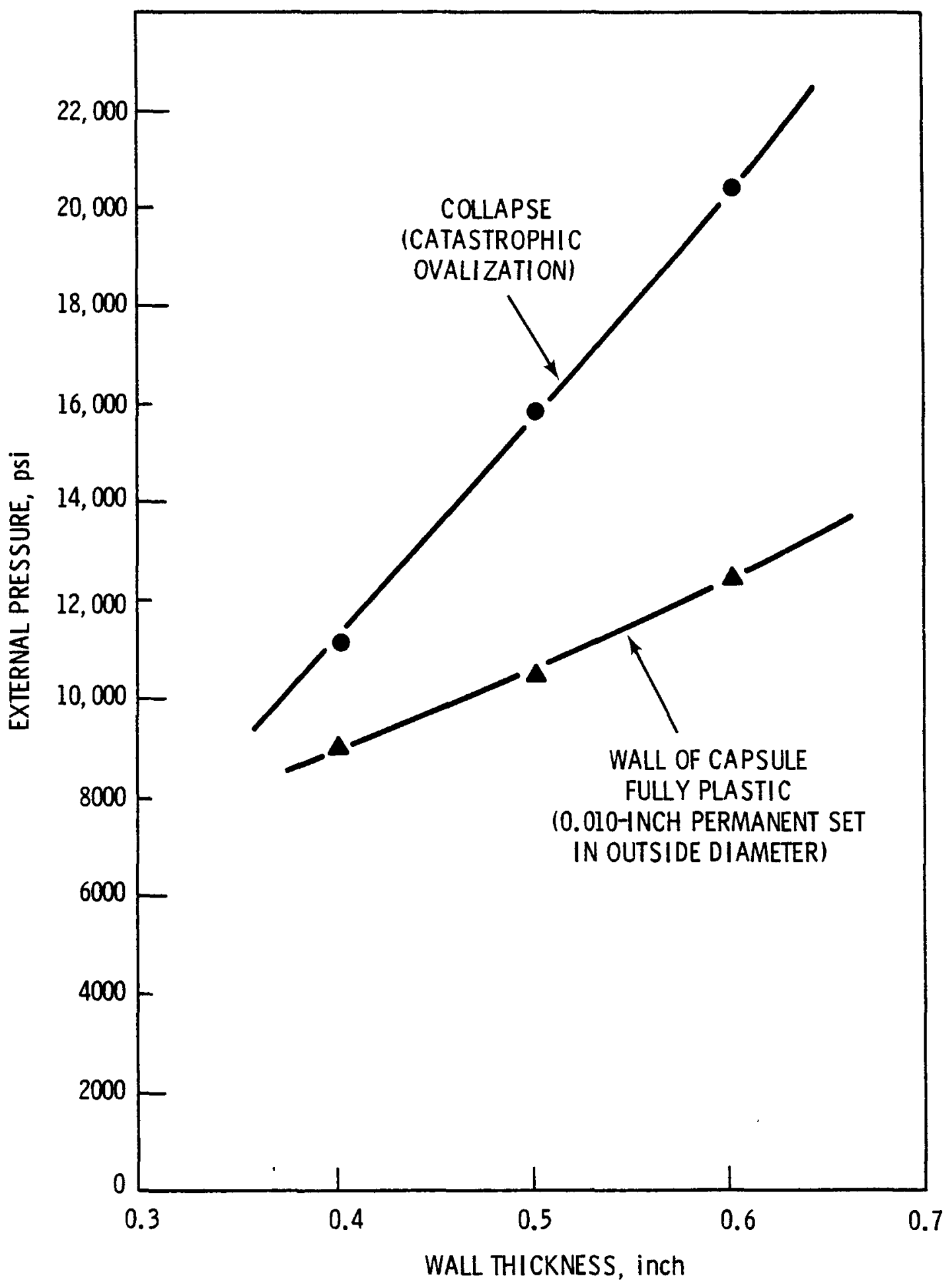

FIGURE 7. Experimental Yield and Collapse Pressures for AISI-1018 Steel Test Capsules 
TABLE 3. Capsule Experimental Failure Pressures

\begin{tabular}{|c|c|c|c|}
\hline & $\begin{array}{c}0.4 \text {-Inch } \\
\text { Wall } \\
\end{array}$ & $\begin{array}{c}0.5 \text {-Inch } \\
\text { Wa11 } \\
\end{array}$ & $\begin{array}{c}0.6-\text { Inch } \\
\text { Wall } \\
\end{array}$ \\
\hline $\begin{array}{l}\text { Pressure for Fully Plastic } \\
\text { Wall of Capsule, psi }\end{array}$ & 9,000 & 10,500 & 12,500 \\
\hline $\begin{array}{l}\text { Pressure for Collapse (Cat- } \\
\text { astrophic Ovalization), psi }\end{array}$ & 11,200 & 15,900 & 20,500 \\
\hline
\end{tabular}

the square of the wall thickness; thus, the thicker-walled capsules had a disproportionately enhanced resistance to ovalization.

Figure 8 shows stra in data obtained from the electrochemically etched grids on the outside surface of the 0.5 -inch wall capsule. Changes in the etched 0.1-inch diameter circles were measured on a circumferential trace and along two longitudinal lines. As indicated, axial strains were small compared to the measured hoop strains. Compressive strains were as high as 50 percent while tensile strains showed a peak of 30 percent. For these strain levels it is likely that rupture of the capsule wall would have occurred had the capsule material been in an embrittled condition and lacked ductility. Such an embrittled condition will exist for the prototype capsule of Hastelioy $S$, due to metallurgical changes that occur with thermal aging. 

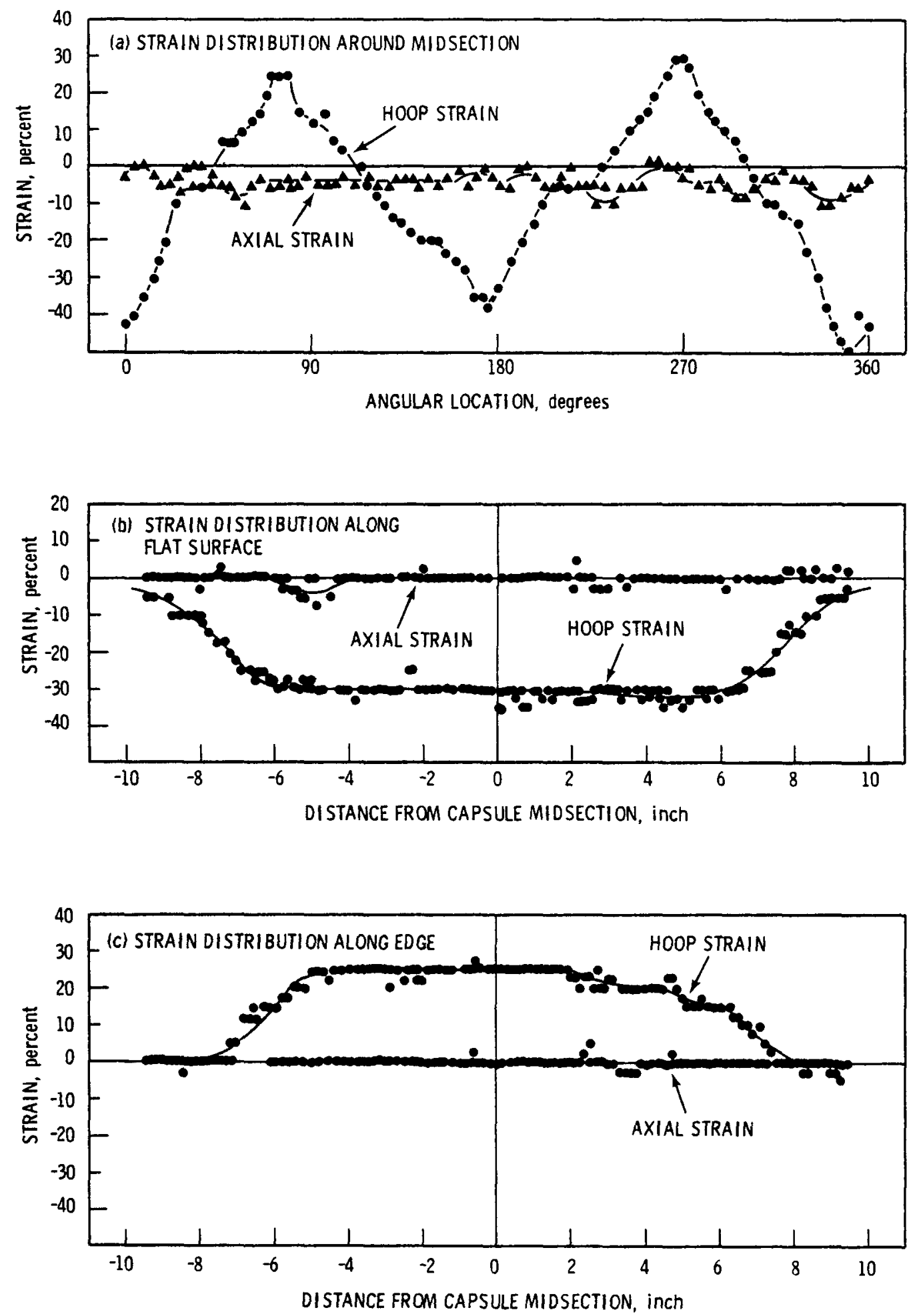

FIGURE 8. Strain Grid Data from Outer Surface of 0.5-Inch Wall Capsule 


\section{STRESS ANALYSIS}

Stresses in the test capsules were calculated to estimate the pressures required to make the full wall of each capsule yield. Both a finite element computer code and approximate equations were utilized. The finite element code ADINA (Bathe 1976) was used to model the capsule geometries including end caps. Incremental elastic plastic analyses were performed based on the von Mises yield criterion with isotropic strain hardening. These finite element calculations were considered more rigorous than the approximate equations, and were expected to agree best with the experimental results.

Equations for average stresses through the capsule wall were formulated in terms of the wall thickness, $t$, outside diameter, $D_{0}$, the inside diameter, $D_{i}$, and the external pressure, $P_{0}$, as follows:

$$
\begin{aligned}
& \sigma_{r}=\text { radial stress }=-P_{0} / 2 \\
& \sigma_{\theta}=\text { hoop stress }=-P_{0} D_{0} / 2 t \\
& \sigma_{z}=\text { axial stress }=-P_{0} D_{0}^{2} /\left(D_{0}^{2}-D_{i}^{2}\right)
\end{aligned}
$$

Effective stresses to evaluate pressures that produce plastic conditions in the capsule are defined as:

- von Mises stress $-2 \sigma^{2}=\left(\sigma_{r}-\sigma_{\theta}\right)^{2}+\left(\sigma_{r}-\sigma_{z}\right)^{2}+\left(\sigma_{\theta}-\sigma_{z}\right)^{2}$

- Tresca stress $-\bar{\sigma}=\sigma_{\theta}-\sigma_{r}$

Yield in the full wall of the capsule was taken to occur when the pressure was sufficient to increase the effective stress $\bar{\sigma}$ to the material yield strength.

Critical pressures for tube collapse in the form of ovalization in the plastic range can be estimated using the equation suggested in Timoshenko and Gere (1961):

$$
\sigma_{c r}=\frac{E_{t}}{1-v^{2}}(t / 2 R)^{2}
$$

where the stress $\sigma_{\mathrm{cr}}$ can be calculated using the above equation for hoop 
stress. The parameter $E_{t}$ is the slope of stress strain curve in the plastic range. Poisson's ratio $v$ may be taken as 0.5 in the plastic range, and the radius $R$ can be interpreted as the mean radius of the tube. The above stability criterion is based on thin wall considerations. For the capsule thicknesses tested here, the equation indicates the important material and geometric parameters governing ovalization. However, numerical predictions of collapse pressures are likely to be approximate. 


\section{PREDICTED VERSUS EXPERIMENTAL COLLAPSE}

Two failure pressures have been defined. The first corresponds to a fully plastic condition in the capsule wall. The second pressure 1 imit was unstable ovalization and catastrophic flattening. For the capsule wall thicknesses of interest, the fully plastic condition must first be present for flattening to occur. Therefore, emphas is has been placed on the capability of analysis methods to predict the fully plastic condition. This prediction should also be more straightforward and accurate than predictions of unstable ovalization.

Figure 9 shows the predicted pressures for gross yield of the capsule wall along with the corresponding experimental data. Al1 predictions give higher failure pressures than observed in the tests. It was initially believed that the finite element analysis would give the most realistic predictions. However, the correlation with the finite element predictions was the least satisfactory with experimental pressures being about 60 percent of the predicted pressures.

Approximate stress formulas were applied in connection with different yield criteria. The von Mises yield criterion applied in this manner to average wall stresses was about 6 percent below the corresponding finite element solutions. The Tresca (or maximum shear stress) criterion agreed better with the experimental trends, but the experimental pressures were still only about 75 percent of the failure pressure predicted by the Tresca criterion.

The final prediction assumed that yield occurred once the mean hoop stress in the capsule wall equaled the material yield strength. This method of prediction neglects the effects of the triaxial stress state in the capsule wall and is contrary to accepted theories of plasticity and the mainstream of experimental data. Nevertheless, the prediction agrees within about 15 percent with the experimental data, which is within characteristic accuracy limits of plasticity theories. 


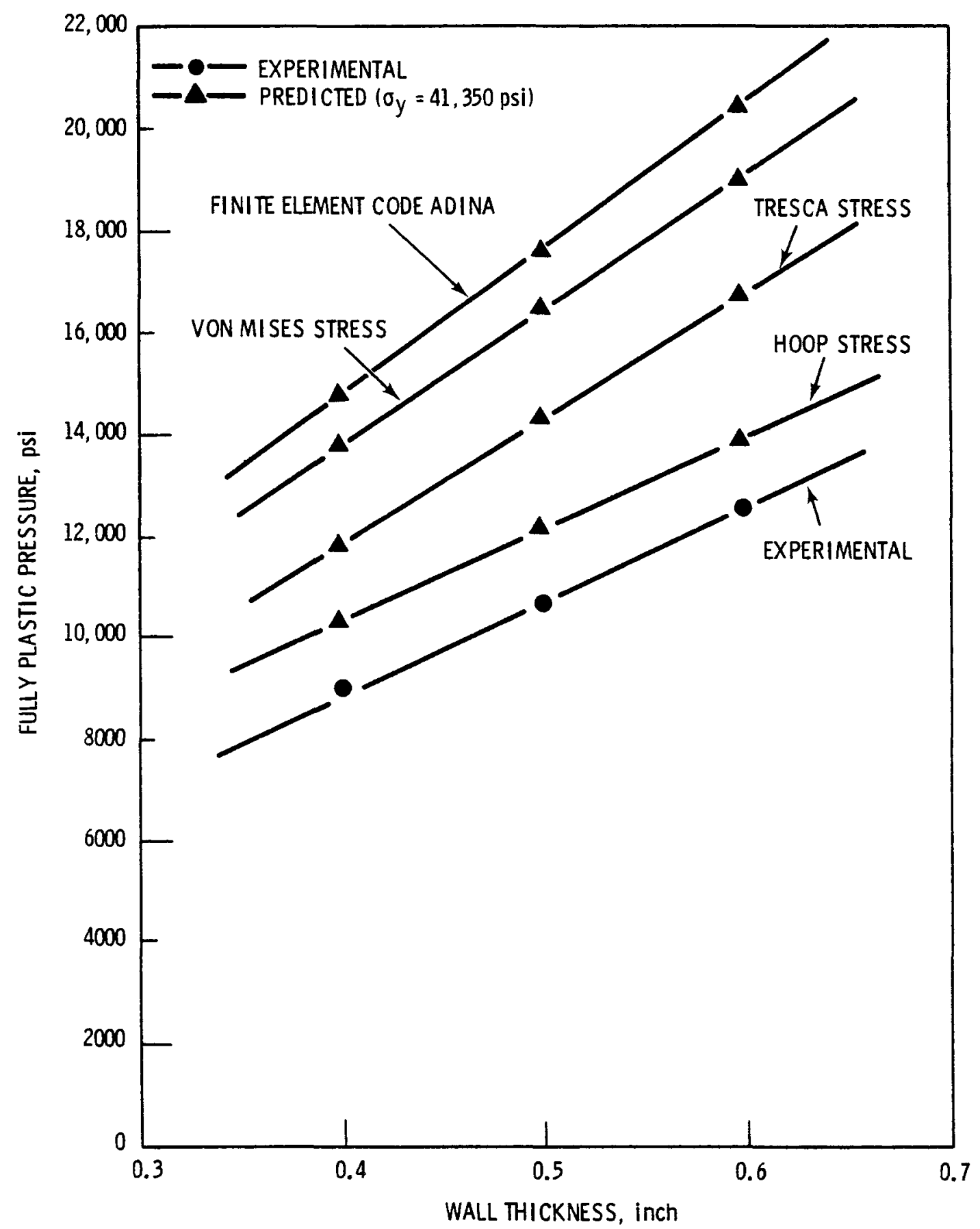

FIGURE 9. Comparison of Predicted and Measured Yield Pressures for AISI-1018 Steel Test Capsules 
The effect of directional yield strength (due to anisotropy of the tubing material as given in Table 1) was not considered in the correlations shown in Figure 9. A compressive yield of $33,900 \mathrm{psi}$ in the radial direction was the lowest yield strength measured. Because the radial stress component was the lowest of the principal stresses, the 33,900-psi yield should be of secondary importance relative to the overall plastic behavior of the test capsules. Nevertheless, if the low radial yield strength is arbitrarily used in connection with the Tresca yield criteria, good agreement with the experimental data can be obtained. This suggests that a slip system related to the low radial yield strength of the AISI-1018 carbon steel may have governed capsule response.

In summary, the correlation between the experimental results and analytical predictions is disappointing. A further disturbing feature is that the correlation is better for the simplistic methods than for the more sophisticated finite element calculations. It appears that classical plasticity theory simply performs poorly for the low carbon steel capsule material under the triaxial compressive stress states present in the external pressure tests.

Both the experimental and finite element results can be normalized with respect to the (measured or predicted) full wall yield pressure, and the results can then be made to correlate quite well. In Figures 10 and 11 finite element results for the 0.5 -inch wall capsule are compared with the test data. The calculations for the 0.4-inch wall were continued into the post-yield region. The finite element model included initial geometric imperfections as determined from capsule measurements. The imperfection was a nonconcentricity of the capsule bore relative to the outside diameter by an offset of 0.005 inch. This offset was inferred from ultrasonic measurements of wall thickness variations. The finite element model consisted of a $180^{\circ}$ arc of the capsule cross section, which was analyzed using the plane strain option of the computer code ADINA. The total Lagrangian formulation for geometric (large deflection) effects was selected, and the external pressure loading was applied as a "follower force" to the capsule surface. The stress-strain curve in Figure 1 was 
converted to a true-stress versus true-strain format, and then curvefitted for the numerical analysis.

Figure 10 shows the predicted average diameter change as a function of pressure after normalization with respect to the calculated capsule yield pressure. In the normalized format the predicted response falls within the scatter of the experimental data. It should be noted that the experimental data were not taken in sufficient detail to define the smooth transition between elastic and plastic behavior as is exhibited by the predicted curve. Further, at the higher pressures (beyond which point the analysis was terminated), the experimental curves show a decreasing slope. This is indicative of the increasing ovalization that was developing in the test capsules at these pressures.

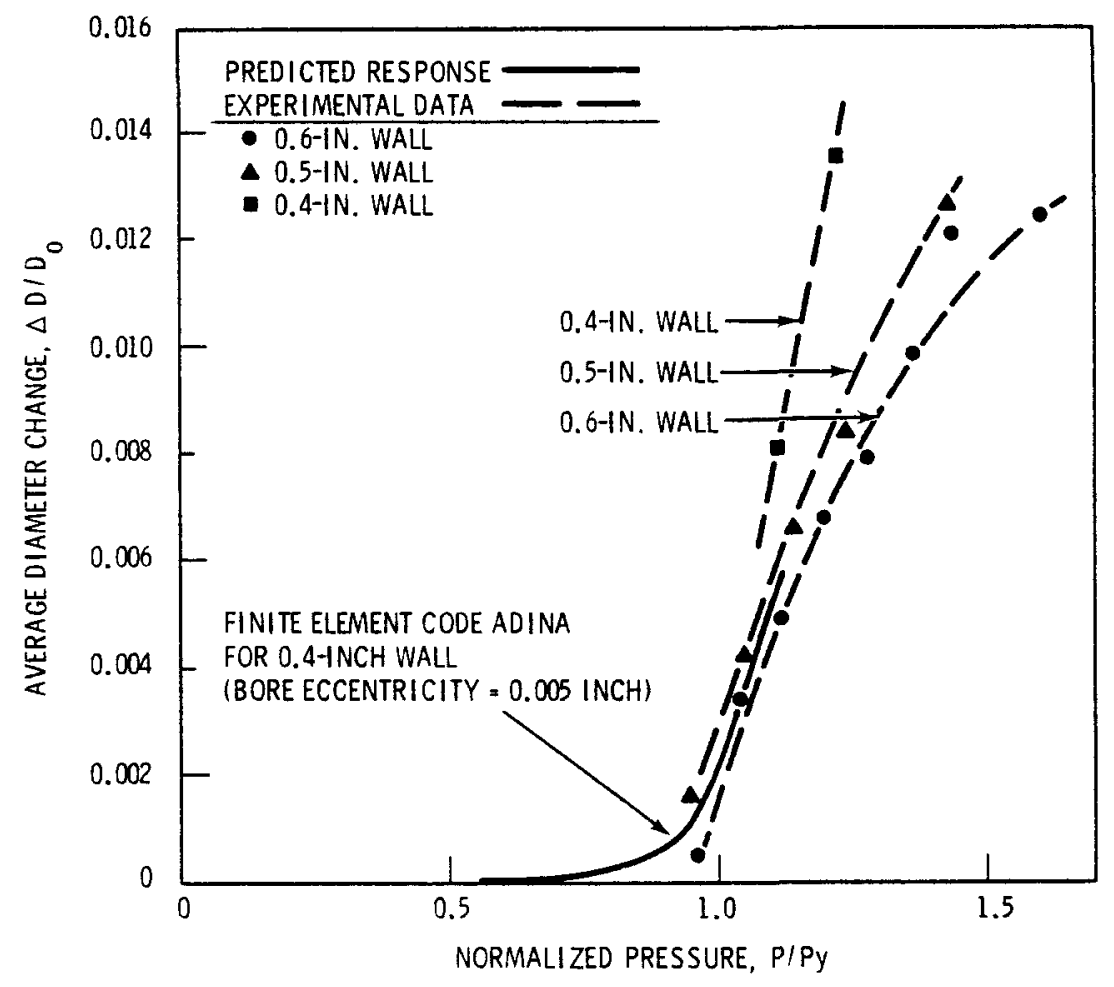

FIGURE 10. Comparison of Predicted and Measured Average Diameter Changes for AISI-1018 Stee1 Test Capsules 
The predicted development of ovalization in the 0.4 -inch wall capsule is shown in Figure 11 . When plotted against normalized pressure, the predicted onset of instability agrees well with the experimental results for the 0.4 -inch wall capsule. The assumed initial bore eccentricity of 0.005 inch was sufficient to initiate an unstable ovalization mode into the finite element calculations. However, as noted before, the analysis was unable to accurately predict the actual pressure for full yielding of the capsule wall $\left(P_{y}\right)$, and this delayed the predicted development of ovalization. In summary, the nonl inear finite element analysis has been shown to predict instability or ovalization in the plastic range. However, accurate prediction requires improved equations to describe yield under the types of multiaxial stress states of interest to the thick-walled capsules.

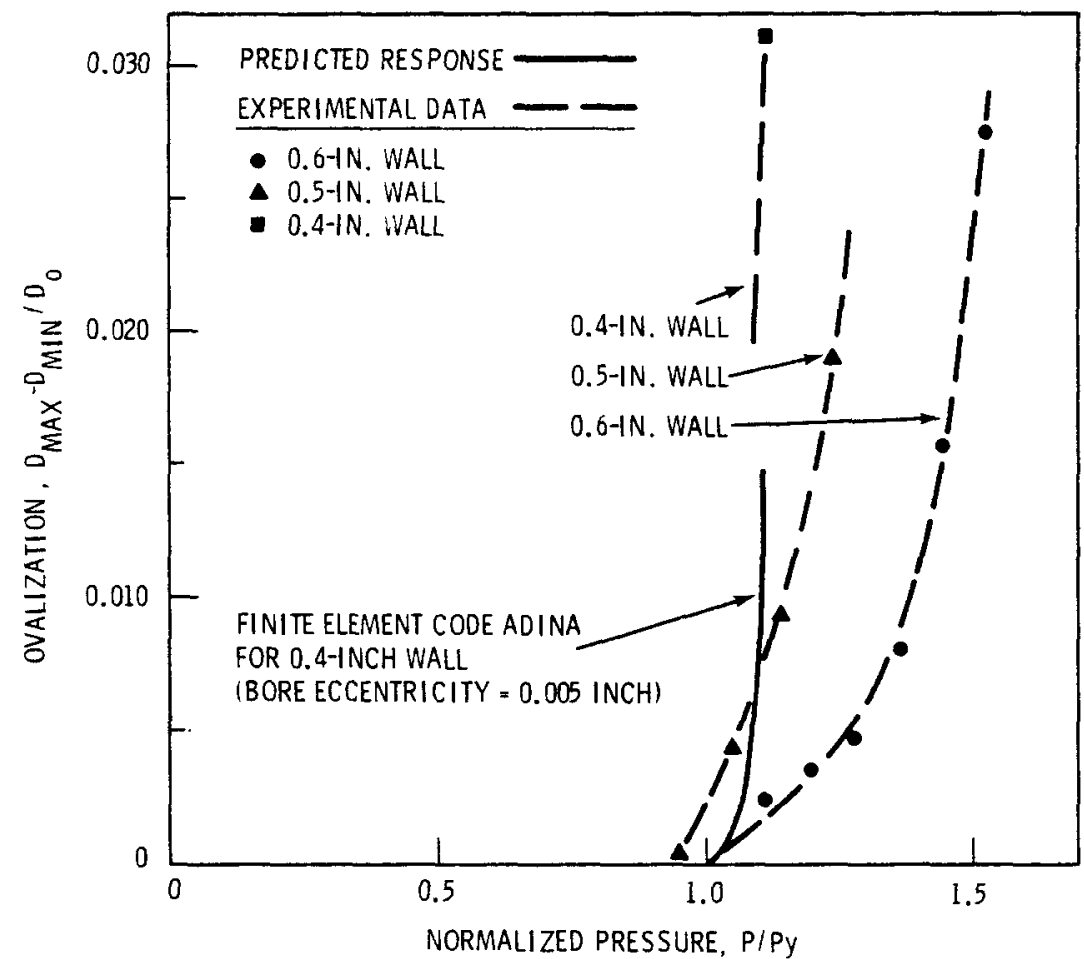

FIGURE 11. Comparison of Predicted and Measured Ovalization of AISI-1018 Steel Test Capsules 
page blank 


\section{POSSIBLE SOURCES OF ERROR}

A number of proposed reasons for the lack of correlation between the predicted and experimental capsule yield behavior have been evaluated. These are discussed below.

\section{GEOMETRIC IMPERFECTIONS}

It is well known that the collapse of tubes under external pressure is often reduced by initial geometric imperfections, particularly the initial ovalization of the ideally circular cross section. However, Heise and Esztergar (1979) show that sensitivity to imperfections decreases as the ratio of tube wall thickness to diameter increases. The wall thickness ratios for the capsules tested were large and imperfections should have had little effect.

Detailed measurements of the capsules showed a small variation in wall thickness around the circumference of the tubes, which was due to eccentricities (on the order of 0.005 to 0.010 inch) of the capsule bores relative to the outside diameters. Detailed finite element calculations have included these eccentricities, and the predicted effect on capsule yield pressure was found to be negligible.

The experimental capsule behavior showed little evidence of premature ovalization due to geometric imperfections or other possible sources such as circumferential variations in mechanical properties. Al1 capsules first clearly exhibited a period of uniform inward plastic flow, and only later began to ovalize.

\section{ANISOTROPY}

The compression tests showed that the yield strength of the tubing material was slightly anisotropic; the radial yield strength was approximately 15 percent less than the circumferential yield. As discussed above, conventional theories of plastic flow in metal would suggest that this difference had only a minor effect on the capsule behavior. 
INSTRUMENTATION ERRORS

A faulty or out-of-calibration pressure gage could have invalidated the experimental data. However, the official pressure data were recorded from a gage that had been calibrated in accordance with the prescribed practice at the Port Hueneme Civil Engineering Laboratory. In addition, a second gage was present to monitor system hydraulic pressures. The readings on this gage were essentially in agreement with the official gage readings.

\section{HEAT TREATMENT NOT AS SPECIFIED}

The capsules and samples for mechanical property tests were annealed prior to tests. If any of the heat treatments had been omitted or done improperly, then misleading results could have been obtained. There is no reason to suspect improper heat treatment. Furthermore, test specimens, including all the compression specimens, were cut from one of the capsules (0.6-inch wa11) after pressure testing and the measured yield strengths were consistent with previous data.

\section{IDENTIFICATION OF COMPRESSION SPECIMENS}

A low compressive yield strength (i.e., low relative to strengths in the axial and circumferential directions of the tube) for the radial direction of the tube was measured. Had the low yield been in the circumferential direction, the experimental trends would have been far more consistent with the stress calculations: The possibility that the radial and circumferential specimens were switched or mislabeled in handling has been considered. This appears unlikely. Evidence shows careful recordkeeping by the machinist. The specimens were systematically labeled, and were clearly identified in subsequent handling.

\section{END CAP EFFECTS}

The presence of end caps on the test capsules tended to prevent collapse near the ends of the capsules. If the capsules were sufficiently short, this restraining effect could increase the observed collapse pressure 
of the capsules. However, finite element calculations were performed to estimate the extent of end effects, and the results indicate that the center portion of the capsules should be essentially unaffected by the end restraint. In addition, any such restraint would have increased the pressure capability of capsules and improved the apparent correlation between the tests and the analytical predictions.

\section{DETECTION OF YIELDING IN CAPSULES}

The occurrence of yielding through the full thickness of the capsule wall was inferred from measurement of the capsule outside diameter. This required some arbitrariness in selecting a permanent change in outside diameter of 0.010 inch as the criterion for full plasticity. The selected criterion did, however, correlate with the rapid decrease in capsule diameter with increasing pressure. It was also consistent with the events associated with full wall plasticity in the analytical studies. Nevertheless, there could be some error of perhaps 5 percent in terms of pressure in defining the occurrence of fully plastic behavior in the test capsules.

\section{RESIDUAL STRESSES}

The presence of residual stresses in the walls of the capsules could affect the capsule behavior. However, these stresses were probably quite low due to the annealing of the capsules before testing. Furthermore, while residual stress could affect the first occurrence of local yielding, they should have little effect once full plasticity develops in the capsule wall.

\section{YIELD CRITERIA}

The yield criteria used in plasticity theories for the plastic behavior of metals have been shown to reasonably approximate various experimental observations. However, for biaxial stress states, errors on the order of 15 percent are not considered unusual. Furthermore, data for triaxial stress states, such as were present in the test capsules, are very limited. For the particular AISI-1018 low carbon steel thick-wall tubing, no data 
were available to evaluate the accuracy of conventional yield criteria. The results of the capsule tests evidently show that existing yield criteria can be in considerable error. The lack of agreement between analyses and experiment in this study is attributed mainly to the inadequacy of the plasticity theories used in the analysis. 


\section{DISCUSSION}

Yield and plastic flow in metals under multiaxial stresses in various loading histories has been the subject of extensive study in the literature. Therefore, data for the materials and stress states relevant to the capsule tests were sought.

Nadai (1950) summarizes much of the classical work on plastic flow in metals. Mechanical test data generally show agreement with analytical predictions using conventional plasticity theories. Such theories assume that the hydrostatic component of stress does not contribute to plastic deformation, al though generalized theories have been formulated that include a pressure dependence of yield. However, experimental data for triaxial stress states are so limited that such theories are largely undeveloped except as mathematical concepts.

Two isolated test results have been noted in which tubing has evidently sustained plastic collapse at lower pressures than predicted. However, the original references were not available to the authors, and details of the tests and the significance of the reported trends could not be evaluated. In tests of oil well casings, Edwards and Miller (1939) obtained an isolated failure well below expected stress levels. The error in prediction was comparable to that for the present capsule study. Llorens (1977) has analyzed compression data for thick-walled tubes from the classical experiments of Bridgeman (1952) and found that theoretical results overestimated the strength of the tubes in question. However, details of the experimental conditions and materials involved were insufficient to draw any general conclusions.

Michno and Findley (1975) have conducted extensive experiments on SAE1017 steel. All data were generated for biaxial stress states. The data show marked changes in the yield surface due to previous plastic deformation (kinematic hardening). Such effects apparently were not important in capsule behavior, because the measured tensile and compressive strengths were comparable. In Michno and Findley's work, the initial yield surfaces 
for biaxial stress generally fit the von Mises yield criterion. However, no triaxial data were presented. 


\section{REFERENCES}

Bathe, K. J. 1976. ADINA - A Finite Element Program for Automatic Dynamic Incremental Nonl inear Analysis. Report 82448-1, Acoustics and Vibration Laboratory, Mechanical Engineering Department, Massachusetts Institute of Technology, Cambridge, Massachusetts.

Bridgeman, P. W. 1952. Studies in Large Plastic Flow and Fracture. McGrawHi11, New York, New York.

Edwards, S. H. and C. P. Miller 1939. "Effect of Combined Longitudinal Loading and External Pressure on the Strength of 0il-Well Casing." Presented to the American Petroleum Institute (Drilling and Production Practice) 1939 meeting, Chicago, I11 inois, pp. 483-502.

Heise, 0., and E. P. Esztergar 1979. "Elastoplastic Collapse of Tubes Under External Pressure." Journal of Engineering for Industry. $92(4): 735-742$.

Llorens, R. E. 1977. "Compression of Thick-Walled Tubes by External Pressure." Journal of Pressure Vessel Technology. 99(4):516-522.

Michno, M. J. and W. N. Findley 1975. "Subsequent Yield Surfaces for Annealed Mild Steel Under Servo-Controlled Strain and Load Histories: Aging, Normality, Convexity, Corners, Bauschinger and Cross Effects." Journal of Engineering Materials and Technology. 97(1):25-32.

Nadai, A. 1950. Theory of Flow and Fracture of Solids. Vol. 1, 2nd ed. McGraw-Hill, New York, New York.

Simonen, F. A., R. J. Shippe11, and D. G. Atteridge 1979. Stress Analysis and Testing of the Outer Capsule Design for the Strontium Heat Source Development Program. PNL-3204, Pacific Northwest Laboratory, Richland, Washington. 


\section{DISTRIBUTION}

No. of

Copies

OFFSITE

A. A. Churm

DOE Patent Division

9800 S. Cass Avenue

Argonne, IL 60439

N. Goldenberg

DOE Advanced Nuclear Systems and

Projects Division

Washington, DC 20545

T. J. Dobry, Jr.

DOE Advanced Nuclear Systems and Projects Division

Washington, DC 20545

T. J. Holleman

DOE Advanced Nuclear Systems and Projects Division

Washington, DC 20545

A. P. Litman

DOE Advanced Nuclear Systems and

Projects Division

Washington, DC 20545

J. J. Lombardo

DOE Advanced Nuclear Systems and Projects Division

Washington, DC 20545

3 W. C. Remini

DOE Advanced Nuclear Systems and Projects Division

Washington, DC 20545

B. J. Rock

DOE Advanced Nuclear Systems and Projects Division Washington, DC 20545
No. of

Copies

N. R. Thielke

DOE Advanced Nuclear Systems and Projects Division

Washington, DC 20545

J. M. Maddox

DOE

E201

Washington, DC 20545

C. A. Cooley

DOE Waste Management Division

Washington, DC 20545

D. C. Davis, Jr.

DOE Oak Ridge Operations office

P.0. Box E

Oak Ridge, TN 37830

W. T. Goldston

DOE Savannah River Operations Office

P.0. Box A

Aiken, SC 29801

27 DOE Technical Information Center

L. J. Jardine

Argonne National Laboratory

9700 South Cass Avenue

Argonne, IL 60439

C. A. Alexander

Battelle Columbus Laboratories

505 King Avenue

Columbus, $\mathrm{OH} 43201$

W. R. Pardue

Battelle Columbus Laboratories

505 King Avenue

Col umbus, $\mathrm{OH} 43201$ 
No. of

Copies

W. J. Zielenback

Battelle Columbus Laboratories

505 King Avenue

Columbus, $\mathrm{OH} 43201$

R. T. Huntoon

E. I. duPont deNemours \& Company Savannah River Laboratory

Aiken, SC 29801

E. H. Cooke-Yarborough

Electronics and Applied Physics Division

Building 347.3, AERE Harwell

Oxfordshire 0X11 ORA

GREAT BRITAIN

H. C. Carney

General Atomic Company

P. 0. Box 81601

San Diego, CA 92138

S. E. Bronisz

Los Al amos Scientific Laboratory

P.0. Box 1663

Los Alamos, NM 87544

R. A. Kent

Los Alamos Scientific Laboratory

P.0. Box 1663

Los Alamos, NM 87544

R. N. R. Mulford

Los Alamos Scientific Laboratory

P.0. Box 1663

Los Alamos, NM 87544

W. T. Cave

Monsanto Research Corporation

Mound Laboratory (DOE)

Nuclear Operations

P.0. 32

Miamisburg, $\mathrm{OH} 45342$
No. of

Copies

R. Dewitt

Monsanto Research Corporation

Mound Laboratory (DOE)

Nuclear Operations

P.0. Box 32

Miamisburg, $\mathrm{OH} 45342$

H. H. Musselman, Tech. Dir.

Department of the Army

Headquarters, U.S. Army

Facilities Engineering Support Agency

Fort Belvoir, VA 22060

Officer in Charge

Lt. J. H. Vogt

Naval Nuclear Power Unit

Code 70

Port Hueneme, CA 93043

2 A. A. Arcuni

Naval Facilities Engineering Command

Office of Special Assistant Nuclear Programs (04N)

200 Stovall Street

Alexandria, VA 22332

F. N. Case

Oak Ridge National Laboratory

Oak Ridge, TN 37830

R. S. Crouse

Oak Ridge National Laboratory

Oak Ridge, TN 37830

K. W. Haff

Oak Ridge National Laboratory

Oak Ridge, TN 37830

J. Hammond

Oak Ridge National Laboratory

Oak Ridge, TN 37830 
No. of

Copies

J. R. Keiser

Oak Ridge National Laboratory

Oak Ridge, TN 37830

E. Lamb

Oak Ridge National Laboratory

Oak Ridge, TN 37830

C. L. Ottinger

Oak Ridge National Laboratory

Oak Ridge, TN 37830

J. C. Posey

Oak Ridge National Laboratory

Oak Ridge, TN 37830

A. C. Schaffhauser

Oak Ridge National Laboratory

Oak Ridge, TN 37830

P. Dick

Teledyne Energy Systems

110 W. Timonium Road

Timonium, MD 21093

R. Hannah

Teledyne Energy Systems

$110 \mathrm{~W}$. Timonium Road

Timonium, MD 21093

W. A. McDonald

Teledyne Energy Systems

110 W. Timonium Road

Timonium, MD 21093

P. Vogel berger

Teledyne Energy Systems

$110 \mathrm{~W}$. Timonium Road

Timonium, MD 21093

C. C. Silverstein

Westinghouse Astronuclear Laboratory

P.0. Box 10864

Pittsburgh, PA 15236
No. of

Copies

ONSITE

4 DOE Richland Operations Office

D. Bogon

W. A. Burns

R. E. Gerton

H. E. Ransom

8 Rockwell Hanford Operations

L. I. Brecke

H. H. Hopkins

J. D. Kaser

E. J. Kosiancic

T. H. May

D. Ramey

J. P. Sloughter

C. R. Stroup

36 Pacific Northwest Laboratory

D. G. Atteridge

A. J. Currie

H. T. Fullam (10)

M. H. Henry

R. P. Marshall

R. E. Nightingale

N. J. 01 son

L. D. Perrigo

A. M. Platt

W. E. Sande

F. A. Simonen (8)

H. H. Van Tuy 1

Technical Files (5)

Publishing Coordination (3) 